\title{
Autoconstrução: estudos de caso sobre os riscos e suas consequências para o autoconstrutor
}

\author{
L.S. Silva ${ }^{1 *}$, C.R. Medeiros ${ }^{2}$. K.R. Batista ${ }^{3}$ \\ Autor de Contato: lucianasouza970@gmail.com*; \\ ${ }^{1}$ Graduada em Engenharia Civil - Centro Universitário UNIESP, Cabedelo, Brasil. \\ ${ }^{2}$ Graduado em Engenharia Civil - Centro Universitário UNIESP, Cabedelo, Brasil. \\ ${ }^{3}$ Professora do Curso de Engenharia Civil - Centro Universitário UNIESP, Cabedelo, Brasil.
}

\section{RESUMO}

A prática da autoconstrução no Brasil é muito comum, principalmente nas áreas de população com renda baixa. A falta de conhecimento técnico para a construção e elaboração de projetos podem gerar um resultado inapropriado, além das perdas materiais e financeiras que podem ceifar vidas. Este trabalho tem por objetivo apresentar os fatores que condicionam este tipo construção, seus riscos e consequências, as principais dificuldades enfrentadas pelo autoconstrutor no decorrer da obra até sua finalização bem como quão valioso é a contratação do profissional técnico habilitado. Por meio de pesquisa exploratória e levantamento bibliográfico, quatro estudos de caso trouxeram resultados que demonstram que a autoconstrução é prática entre os entrevistados e que estes refletem uma tradição cultural enraizada, os quais indicam que ao buscar apoio técnico estão aumentando os custos da obra.

Palavras-chave: Autoconstrução. Profissional habilitado. Construção civil. Riscos. Consequências 


\title{
Self-construction: case studies on risks and their consequences for the self- builder
}

\begin{abstract}
The practice of self-construction in Brazil is very common, especially in areas with low-income population. The lack of technical knowledge for the construction and elaboration of projects can generate an inappropriate result, in addition to material and financial losses that can claim lives. This work aims to present the factors that condition this type of construction, its risks and consequences, the main difficulties faced by the self-builder during the work until its completion, as well as how valuable it is to hire a qualified technical professional. Through exploratory research and bibliographical survey, four case studies brought results that demonstrate that selfconstruction is practical among the interviewees and that they reflect a deep-rooted cultural tradition, which indicate that when seeking technical support, the costs of the work are increasing.
\end{abstract}

Keywords: Self-construction. Qualified professional. Construction. Scratchs. Consequences.

\section{Autoconstrucción: estudios de casos sobre riesgos y sus consecuencias para el autoconstructor}

\section{RESUMEN}

La práctica de la autoconstrucción en Brasil es muy común, especialmente en áreas con población de bajos ingresos. La falta de conocimientos técnicos para la construcción y elaboración de proyectos puede generar un resultado inadecuado, además de pérdidas materiales y económicas que pueden cobrar vidas. Este trabajo tiene como objetivo presentar los factores que condicionan este tipo de construcciones, sus riesgos y consecuencias, las principales dificultades a las que se enfrenta el autoconstructor durante la obra hasta su finalización, así como lo valioso que es contratar a un profesional técnico cualificado. A través de una investigación exploratoria y un relevamiento bibliográfico, cuatro estudios de caso arrojaron resultados que demuestran que la autoconstrucción es práctica entre los entrevistados y que reflejan una arraigada tradición cultural, lo que indica que al buscar apoyo técnico, los costos de la obra están aumentando.

Palabras clave: Autoconstrucción. Profesional calificado. Construcción civil. Arañazos. Consecuencias.

\section{INTRODUÇÃO}

A autoconstrução é uma realidade no Brasil principalmente nas pequenas cidades e periferias. Uma pesquisa realizada pelo Conselho de Arquitetura e Urbanismo aponta que uma parcela de 85\% da população construiu ou reformou sem auxílio de um profissional tecnicamente habilitado, seja ele 
engenheiro ou arquiteto e que "de modo geral, a contratação de profissionais especializados está ligada à renda e à escolaridade" (CAU/BR - DATAFOLHA, 2015). De acordo com Bonduki (1998), a autoconstrução é uma modalidade de construção onde o morador atua como o principal agente na provisão de sua moradia, indo desde a escolha do terreno até a construção da habitação. Muitas são as denominações atribuídas a essa forma de construir: casas domingueiras, casas de periferia, casas autoconstruídas, casas de mutirão. Devido à falta de critérios no gerenciamento e planejamento, as construções não têm cuidados prévios essenciais e principalmente nota-se a inexistência de apoio técnico por profissionais habilitados, gerando assim futuras ampliações e retrabalhos constantes. A baixa qualidade dessas construções também é uma forte característica (KOWALTOWSKI e PINA, 1995). Sem dúvida os maiores adeptos a esse modo de construção é a população de baixa renda tendo como fator principal a falta de recursos financeiros e em muitos casos à falta de informação. A autoconstrução é tida como uma solução para suprir a necessidade de habitação dessa população pois, os próprios moradores participam de forma direta na construção de suas casas (MARICATO, 1979). O estudo no contexto dessa realidade apresenta uma grande importância aos adeptos da construção empírica que são baseados pelos conhecimentos "copiados" e apoiados nas experiências obtidas ao longo dos anos. A Falta de conhecimento acerca das burocracias necessárias para regularização das construções é bem comum em autoconstruções, os proprietários não buscam informações sobre as documentações necessárias para regularizar sua construção e estarem amparados para que sua obra não sofra embargos e/ou multas (MARICATO,1979). Mas o que seria uma construção irregular? Segundo Werna (2001), trata-se de algo que está fora da norma, implicando no desrespeito aos princípios mais básicos da construção civil, como por exemplo a não observância ao uso e ocupação do solo, desrespeito ao recuo e até mesmo a invasão de terreno público ou terreno vizinho. A deficiência dos processos construtivos é real, e gera manifestações patológicas que surgirão em algum momento, em curto ou longo prazo que comprometem a qualidade da edificação e algumas delas podem trazer consequências negativa à saúde dos usuários (BRAGA, 2001). A autoconstrução está sujeita à diversos riscos desde à falta de segurança da edificação em si e a exposição dos trabalhadores durante a execução da obra. A norma de desempenho ABNT NBR 15.575/2013 (Edificações habitacionais - Desempenho), prevê requisitos mínimos que promovem segurança, durabilidade e qualidade às construções; para que as edificações ofereçam segurança no seu uso e operação. Todo o processo construtivo interfere de forma direta no desempenho da habitação, os autoconstrutores por não possuírem conhecimento técnico acabam não prevendo alguns erros que podem pôr em risco a segurança da edificação a curto ou longo prazo. A exposição dos trabalhadores a acidentes durante a execução da obra é algo corriqueiro, visto que os autoconstrutores não seguem as orientações das normas de segurança submetendo esses trabalhadores a eventuais acidentes de trabalho, quando sequer utilizam os Equipamentos de Proteção Individual - EPI's (ABNT NR 6, 1978), estando totalmente sujeitos e expostos aos riscos de acidente de trabalho tais como: quedas, choques elétricos, perfurações, problemas na pele entre outros. A LEI $\mathrm{N}^{\circ} 11.888$, de dezembro de 2008, "assegura às famílias de baixa renda assistência técnica pública e gratuita para o projeto e a construção de habitação de interesse social." Porém nota-se que no país a exploração do que prevê a lei ainda é bem inibida, a população não tem conhecimento acerca da possibilidade de obter assistência técnica junto à prefeitura, em consequência acabam se submetendo aos riscos que à autoconstrução sugere. Essa assistência evitaria as reformas e ampliações mal planejadas, a baixa qualidade construtiva, os custos excessivos, uso de materiais de baixa qualidade e falta de segurança construtiva.

O objetivo principal deste trabalho é apresentar edificações que foram construídas com recursos precários e mão de obra não especializada e apurar os fatores que levam à autoconstrução, tendo o modo empírico de construir como o sistema construtivo adotado. A análise tem a finalidade de 
mostrar como esse modo de construir é real e trazer conscientização dos riscos e a necessidade de se contratar um profissional tecnicamente habilitado como o engenheiro civil.

\section{ESTUDOS DE CASO}

Este estudo contempla a experiência de quatro edificações residenciais. Onde através de visitas foram realizados levantamento fotográfico, levantamento arquitetônico e aplicação de questionário com o objetivo de analisar os proprietários/autoconstrutor e entender o fator influenciador da adoção desse método de construir e suas principais dificuldades no decorrer da obra até sua finalização.

Os casos I, II e III são de residências localizadas na cidade de Gurinhém-PB. O caso IV é de uma edificação localizada na cidade de João Pessoa- PB.

\subsection{Caso I}

A residência encontra-se na fase inicial de sua construção, trata-se de uma residência unifamiliar um dos exemplos mais típicos de autoconstrução, construída com mão de obra participativa (amigos e familiares) e remunerada.

$\mathrm{O}$ autor principal do projeto foi o próprio morador que relata: "como tenho um pouco de conhecimento, eu mesmo fiz a planta baixa e conversei com alguns amigos e em seguida mostrei ao pedreiro", algo muito comum na autoconstrução como mostra a Figura 1, o proprietário pensa nas disposições dos cômodos e confia a execução ao pedreiro que por sua vez apoia-se nas suas experiências adquiridas por observações e prática.

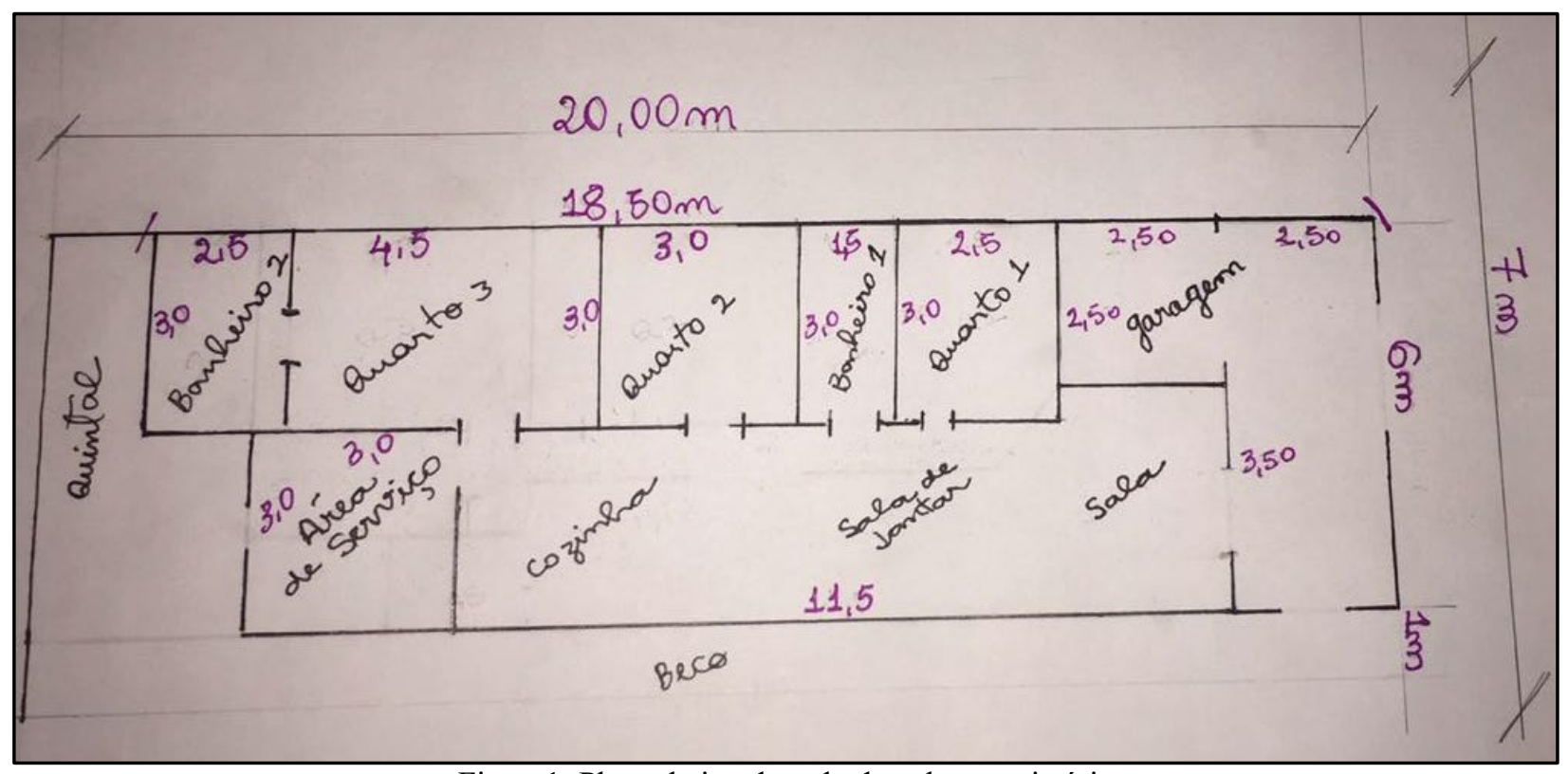

Figura1: Planta baixa desenhada pelo proprietário

\subsection{Caso II}

$\mathrm{O}$ segundo caso nos mostra uma residência unifamiliar com térreo e mais dois pavimentos. $\mathrm{O}$ pavimento térreo será usado como salão de recepção para festas, o segundo pavimento será 
habitação e o terceiro a área de lazer. A construção encontra-se em processo de construção. Foram previstas três etapas até a finalização da obra, cada etapa é feita em um intervalo de um ano.

A edificação tem um ano de construída, a área total do terreno é de $184,00 \mathrm{~m}^{2}$ e área construída de $105,00 \mathrm{~m}^{2}$. A laje utilizada foi a pré-moldada treliçada com lajotas EPS (Isopor).

Dentre algumas observações destacamos a ausência de uso de EPI's pelos funcionários como prevê a NR 35 (Figura 4), e ausência de recuo lateral (Figura3).

Esta obra executada por um pedreiro experiente, o qual demonstra ter bons conhecimentos, adquiridos no exercício de sua atividade profissional. Nota-se que os processos construtivos foram bem pensados, as alturas dos elementos estruturais são proporcionais, porém observa-se que seus conhecimentos adquiridos o levam a trabalhar sob possível superdimensionamento desses elementos, o que pode gerar custos desnecessários, porém contribui para uma maior segurança estrutural; a mão de obra foi $100 \%$ remunerada. Não houve etapa de ajuda mútua.

O principal autor do projeto foi o proprietário sob orientação do pedreiro contratado. O proprietário relata que sua maior dificuldade se deu na definição da dimensão dos cômodos e suas divisões; a escolha e definição dos materiais é dada pela qualidade dos mesmos.

Toda estrutura foi definida e dimensionada pelo pedreiro desde a fundação até a laje de coberta no cabeçalho da planta desenhada pelo pedreiro (Figura 2) é possível ver o quantitativo dos vergalhões, e pregos utilizados: 140 vergalhões $\mathrm{N}^{\mathrm{o}} 10$; 104 vergalhões $\mathrm{N}^{\mathrm{o}} 4.2$; 350 estribos 11x17; $5 \mathrm{Kg}$ de prego caiba; $5 \mathrm{Kg}$ de prego ripa; $10 \mathrm{Kg}$ de arame.

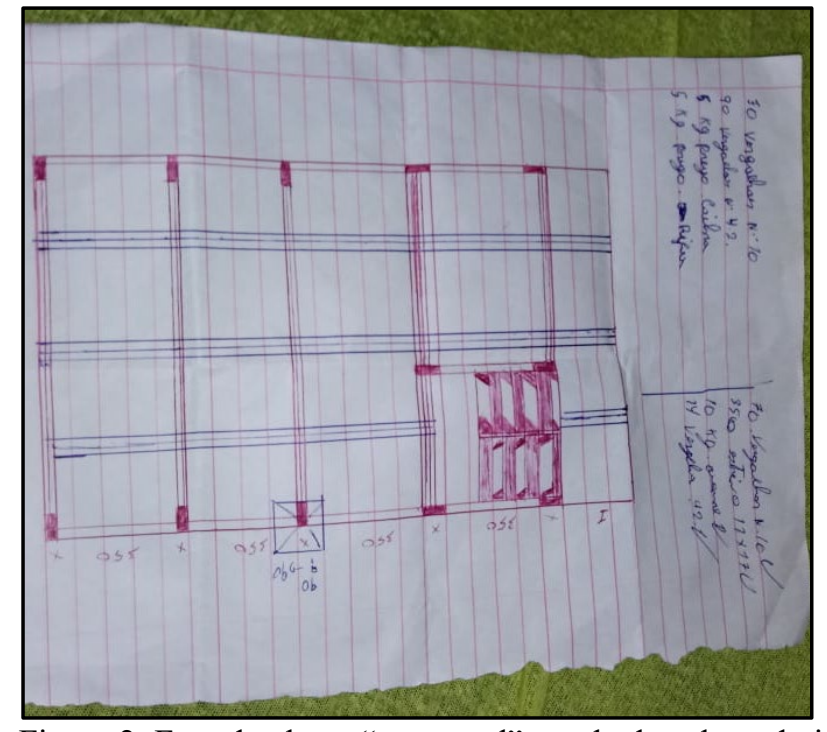

Figura 2: Foto da planta "estrutural" esenhada pelo pedreiro

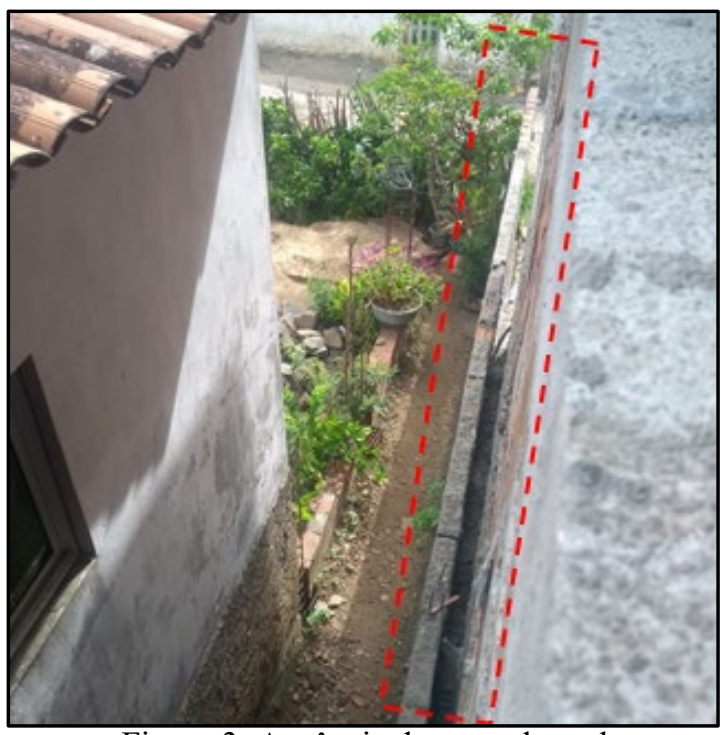

Figura 3: Ausência de recuo lateral 


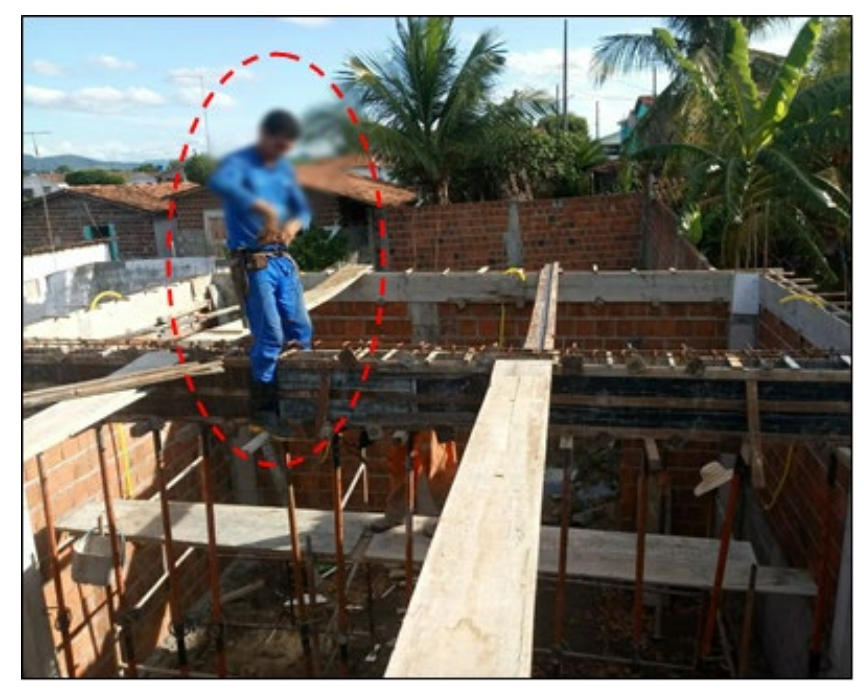

Figura 4: funcionário sem uso dos EPI'S

\subsection{Caso III}

O estudo de caso III contempla uma residência construída há dois anos. O lote possui uma área de $140,00 \mathrm{~m}^{2}$ e área total construída de $153,00 \mathrm{~m}^{2}$ (térreo + pavimento superior).

O projeto foi elaborado pelo proprietário. Parte da obra teve mão de obra remunerada, porém o proprietário participou ativamente da execução, ampliações e reformas. O projeto não contemplou recuos laterais como a maioria das edificações autoconstruídas.

As Figuras 5 e 6 apresentam os levantamentos arquitetônicos realizados no local com destaque às indicações temporais das fases de ampliação da edificação. Atualmente a ampliação encontra-se na $4^{\circ}$ fase. As Figuras 7 e 8 apresentam a fotografia da escada e de sua estrutura.

FASE I - Contemplou o pavimento térreo, até a laje que posteriormente receberia parte do pavimento superior.

Cabe destacar que as vigotas treliçadas para concepção da laje foram produzidas e moldadas "in loco", pelo pedreiro não respeitando o devido dimensionamento, apresentam vazios de concretagem, popularmente conhecidos como "bicheiras", e armadura aparente (Figuras 7 e 8). O piso da escada apresenta variedade nas suas medidas, os pisos variam entre $28 \mathrm{~cm}$ e $32 \mathrm{~cm}$ embora as medidas estejam dentro do que a NBR 9050 - (Acessibilidade a edificações, mobiliário, espaços e equipamentos urbanos) prevê, as dimensões não são constantes, já a altura dos espelhos varia entre $18 \mathrm{~cm}$ e $20 \mathrm{~cm}$, a norma prevê alturas dos espelhos entre $16 \mathrm{~cm}$ e $18 \mathrm{~cm}$. (NBR 9050, 2004).

FASE II - Início da construção do pavimento superior.

FASE III - Trata-se de uma edícula (puxadinho) construído no fundo da residência.

FASE IV -Nas visitas realizadas observamos que os escoramentos foram feitos de forma bem artesanal com o que se tinha em mãos. Outro fato constatado foi a medida da altura das vigas, é comum entre os projetistas adotar $10 \%$ do comprimento do vão para definição da altura das vigas, neste caso as vigas em questão medem em torno de $22 \mathrm{~cm}$ e o vão possui $3,00 \mathrm{~m}$, embora a NBR 6118/14 - Projeto de estruturas de concreto - Procedimento não cite uma altura pré-definida para vigas, levando em consideração que não há um controle quanto à resistência do concreto utilizado e cuidado nas escolhas das armadura e seus devidos espaçamentos, a edificação está sob um risco elevado de apresentar problemas estruturais. Na Figura 9, destacamos um furo feito na viga para passagem das instalações hidráulicas, esse furo pode comprometer a resistência da viga aos esforços e momentos a NBR 6118/14 determina uma série de critérios para quando houver a necessidade de furos nos elementos estruturais, uma das recomendações é que o furo não seja feito próximo aos apoios. A Figura 10 mostra as encanações expostas às intempéries. 


\subsubsection{Levantamento Arquitetônico da Habitação CASO III:}

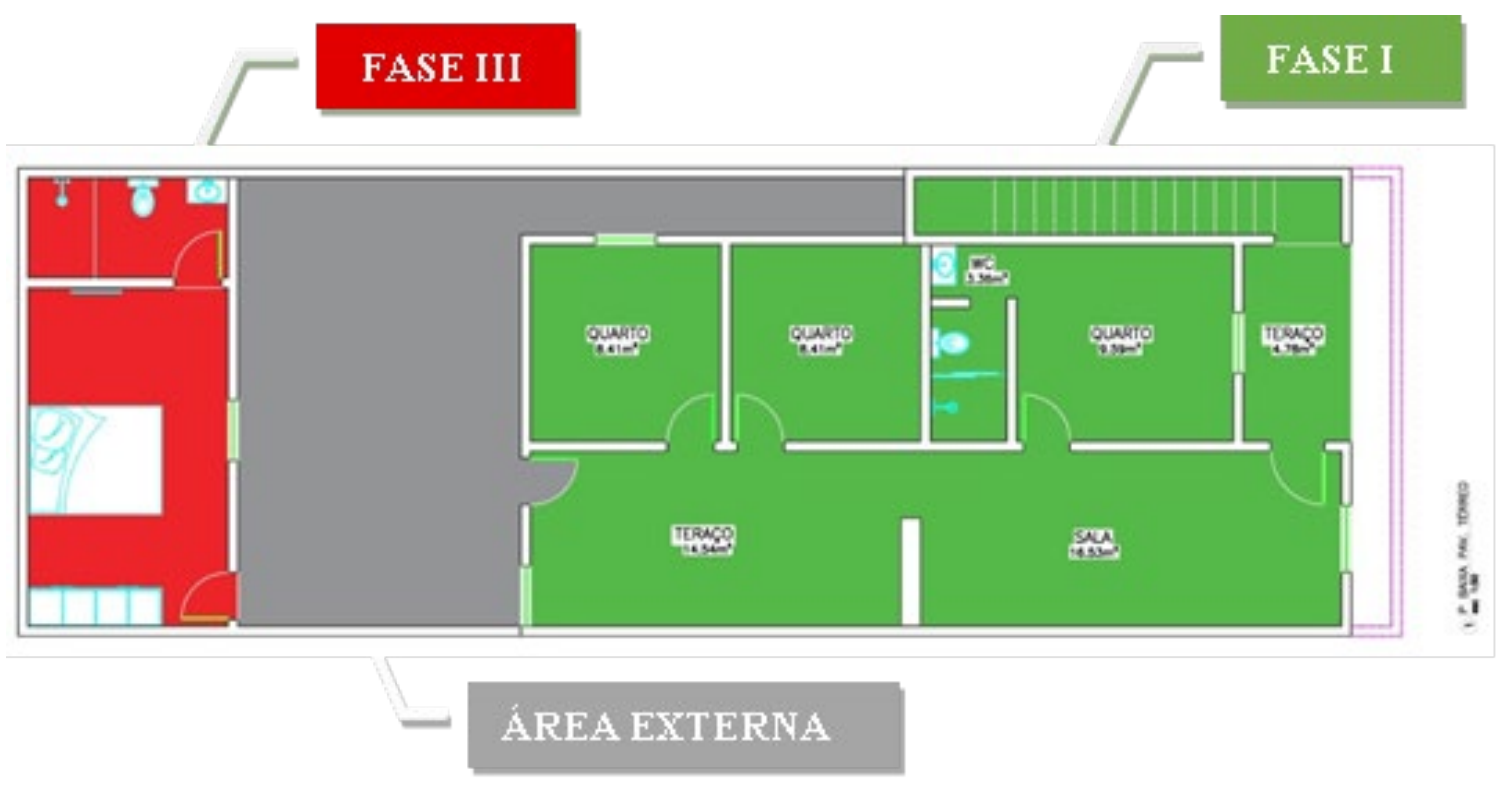

Figura 5: Destaque das fases de ampliações Pav. Térreo, Caso III

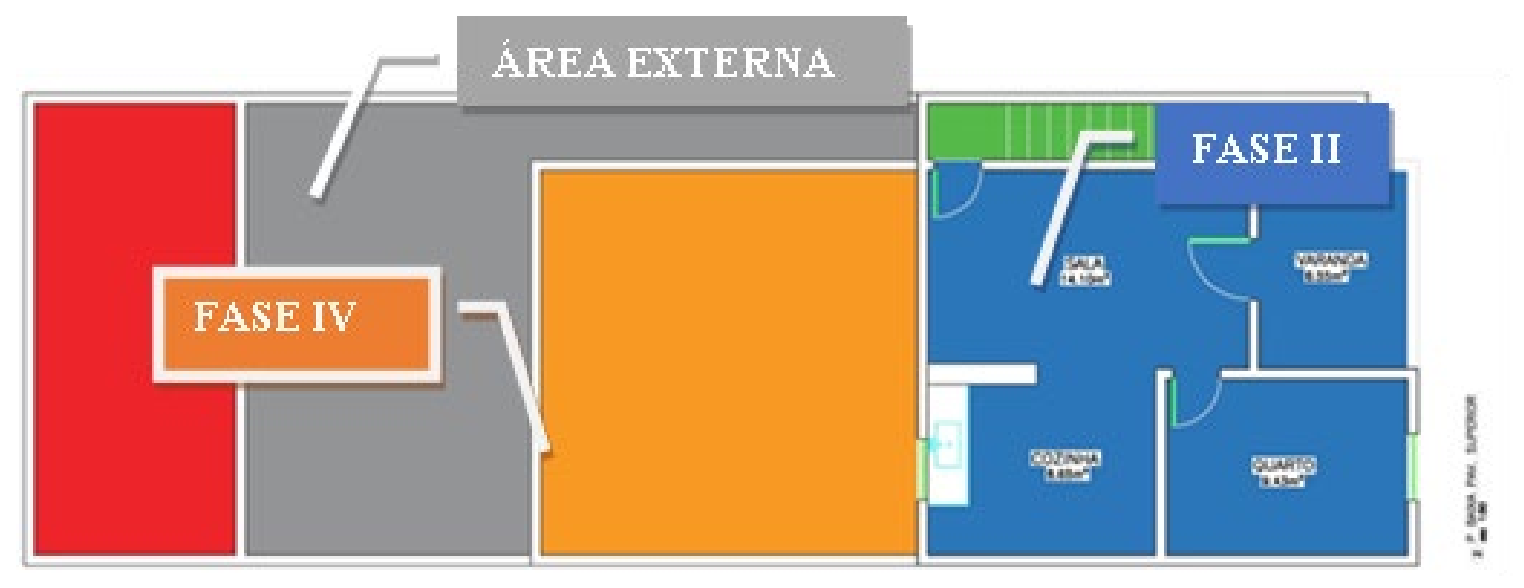

Figura 6: Destaque das fases de ampliações Pav. Superior, Caso III 


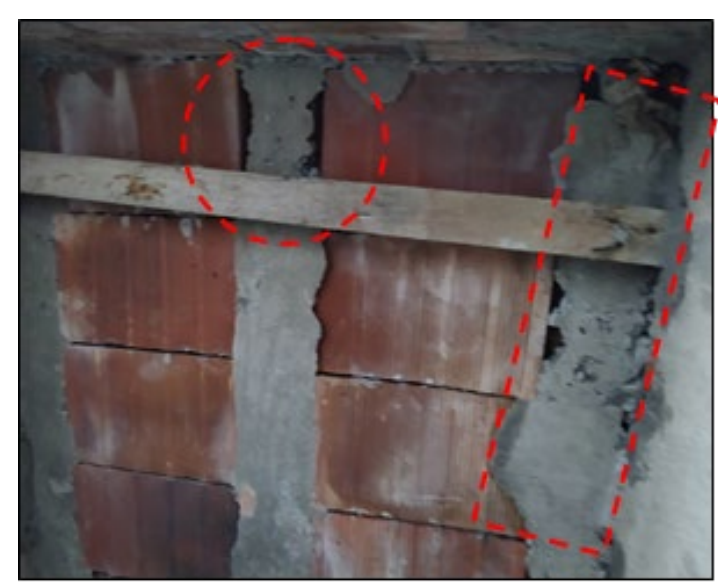

Figura 7: Detalhe de "bicheira" na vigota treliçada

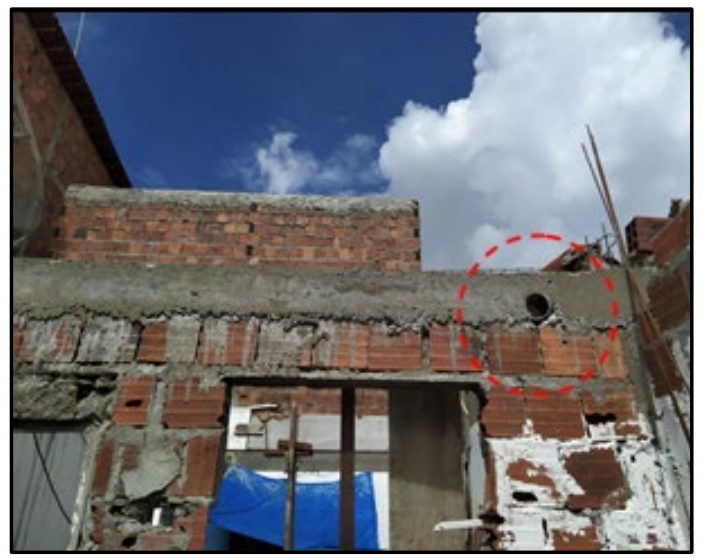

Figura 9: Furo na viga, feito para passagem das instalações hidráulicas.

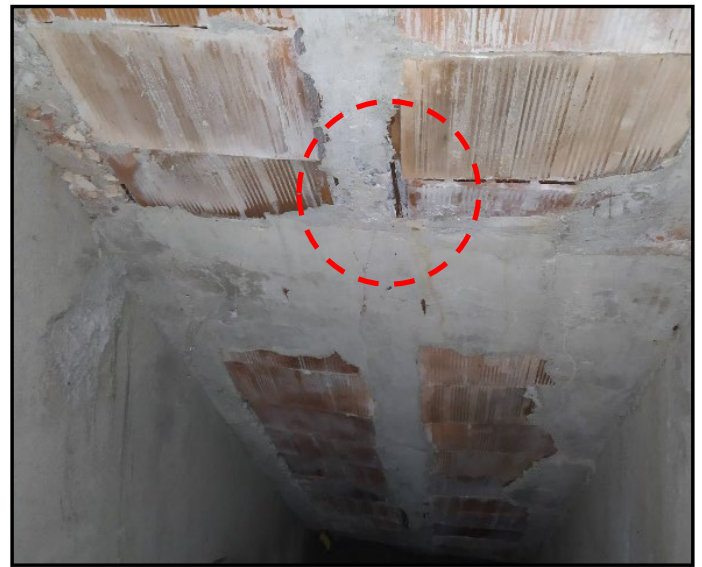

Figura 8: Armadura aparente

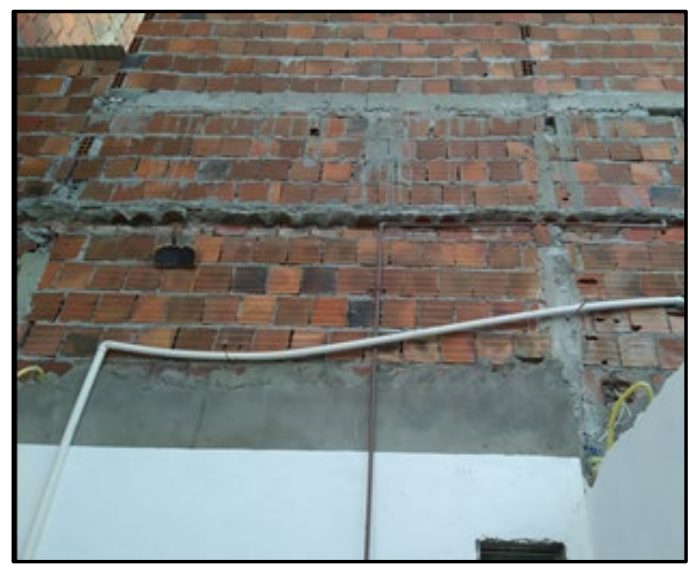

Figura 10: Encanações aparentes, expostas as intempéries

\subsection{Caso IV}

O último caso é de uma residência unifamiliar localizada no bairro de Muçumago, João Pessoa, Paraíba, onde o proprietário informou que o mesmo a construiu. A casa foi construída a cerca de 12 anos, sem consulta à um profissional de engenharia civil. Os métodos construtivos foram realizados conforme experiências passadas do proprietário. Com o passar do tempo a casa apresentou manifestações, tais como: fissura, infiltração, trincas, mal funcionamento da instalação elétrica, neste caso percebeu-se a ausência de quadro de distribuição elétrico.

Como essa construção já tem 12 anos de edificada foi possível observar diversas manifestações patológicas, muitas delas, provavelmente, advindas da construção executada sem o devido acompanhamento técnico. A partir dos registros fotográficos trataremos sobre algumas dessas fissuras que acabam incomodando esteticamente e visualmente, tais manifestações patológicas podem interferir na durabilidade na edificação e trazer alterações na característica da estrutura.

De acordo com Paulo Grandiski (2010 p. 1 apud Corsini):

"Em uma visão geral, simplificada, as origens das fissuras de uma edificação podem surgir na fase de projetos $\neg$ arquitetônico, estrutural, de fundação, de instalações $\neg$, de execução da alvenaria, dos vários sistemas de acabamento e, inclusive, na fase de utilização, por mau uso da unidade".

As Figuras 11 refere-se a uma fissura localizada no hall de entrada da residência, a qual, conforme estudos elaborado por Ercio Thomaz (2010 p. 3 apud Corsini), provavelmente é proveniente da vibração provocada pelos veículos trafegando na rua, bem como proximidades com obras, situações que podem ter favorecido o surgimento das fissuras, pois vibrações contribuem para tal 
quando não se seguem normas construtivas e/ou se executa uma obra sem acompanhamento técnico, visto que as fundações podem ter sido assentadas em camada inadequada do solo, provocando recalque; ou mesmo pela ausência de vergas e contravergas, elementos componentes do sistema de vedação em alvenaria; outros exemplos de erros construtivos que colaboram para o defeito: Formulação do produto e erros na aplicação, carga do uso calculada inadequadamente, problemas com o fluxo de água ou lençol freático, falhas de execução, ausência de projeto e muitos outros.

A Figura 12, refere-se a uma fissura localizada na parte superior da porta de entrada da residência, fissura como essa geralmente são superficiais e menos preocupantes e não ocasionam perigos às estruturas nem aos moradores principalmente por ser uma parede não estrutural (no caso desta moradia). Segundo Thomaz geralmente, fissuras na alvenaria representam menos riscos do que em vigas e pilares. (Thomaz, 2010 p. 3 apud Corsini), ocasionalmente são causadas por mudanças de temperatura, descolamento dos materiais (material de qualidade inferior instalado).

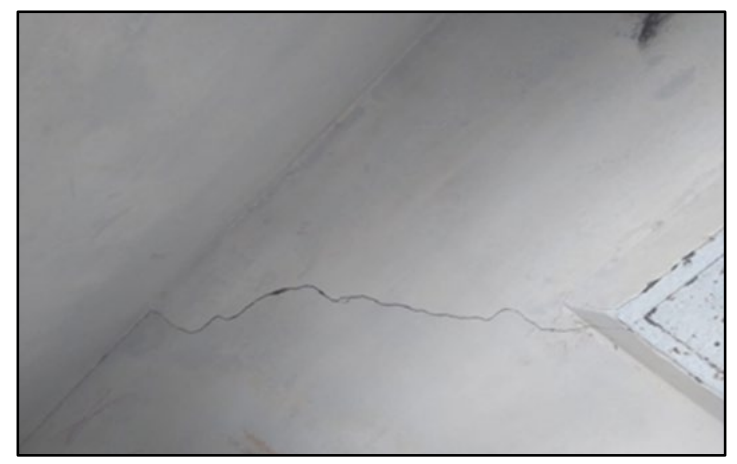

Figura 11: Fissura no hall de entrada

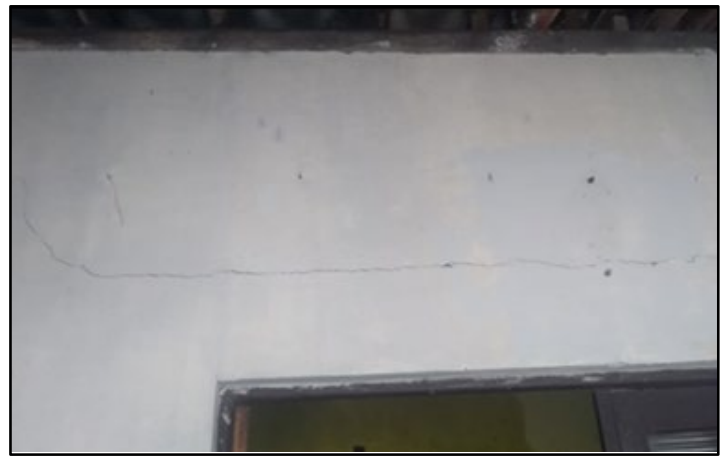

Figura 12: Fissura acima da porta de entrada

As Figuras 13 e 14 são de uma infiltração de grandes proporções na sala trazendo diversos transtornos aos moradores. A infiltração se apresenta nos sentidos ascendentes. A falta da correta aplicação de técnicas construtivas e acompanhamento técnico certamente levaram a uma execução de fundação e alvenaria sem nenhum tipo de impermeabilização, o que provoca infiltração por capilaridade; bem como negligência na execução do telhado provocando infiltrações quando chove, visto que a água desce pela parede. A moradia se torna, portanto, um ambiente úmido, onde se apresenta "mofos" nos móveis e doenças respiratórias.

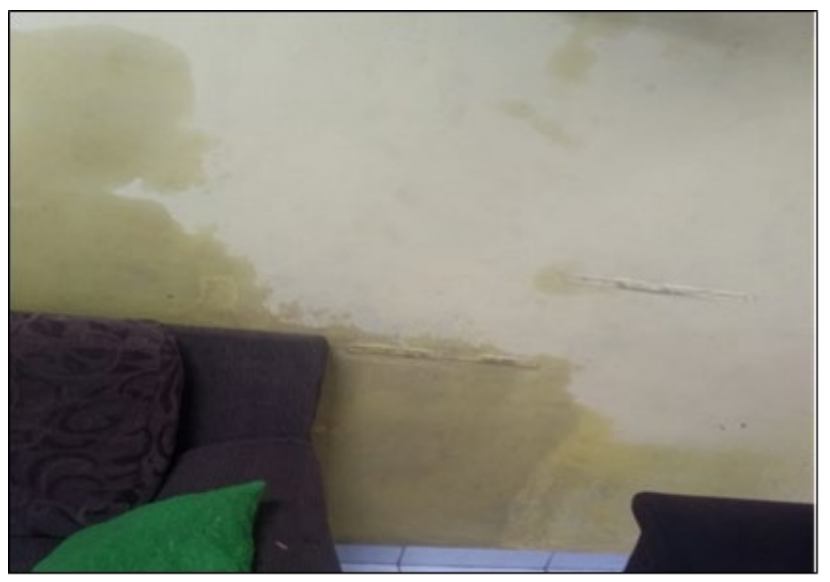

Figura 13: Infiltração da Sala

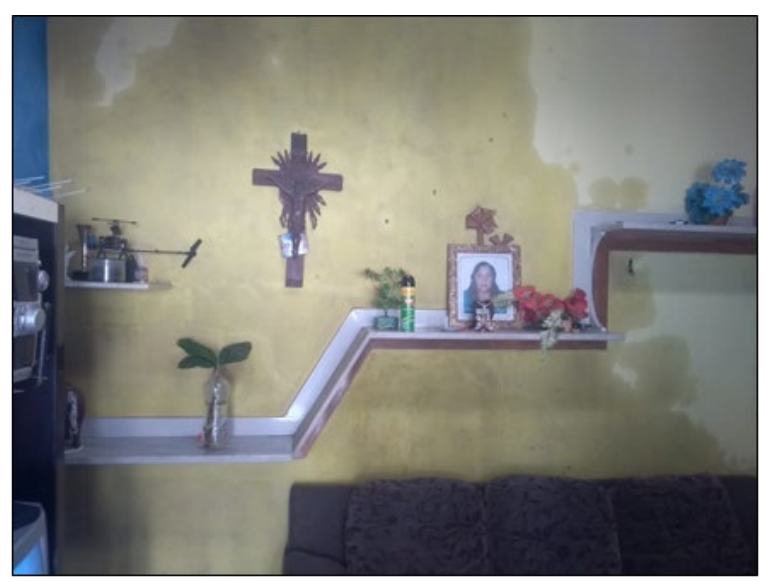

Figura 14: Infiltração da Sala 


\section{RESULTADOS}

Com base nas entrevistas e observações in loco percebe-se que a autoconstrução é prática entre os entrevistados, as quais são reflexos de tradições culturais enraizadas. A busca por dicas e conselhos dos pedreiros e amigos com certa experiência no decorrer da obra é bem comum. Nota-se que os processos de produção adotados estão totalmente fora dos padrões normativos, são executados de forma artesanal, há falta da critérios na definição e dimensionamento dos elementos estruturais, sendo estes definidos por observação e comparação de experiências anteriores.

Verificou-se também total falta de elaboração ou mesmo um esboço simples de projetos de instalações hidrossanitárias e elétrico, não há nenhum tipo de dimensionamento, as tubulações, responsáveis pelas instalações hidrossanitárias geralmente encontram-se expostas às intempéries o que compromete sua vida útil. Em todos os casos não respeitaram os afastamentos laterais.

Para entender o fator influenciador da adoção da autoconstrução e as principais dificuldades enfrentadas pelos proprietários foi realizada uma entrevista com perguntas básicas quanto ao projeto, materiais utilizados, mão de obra e importância da ajuda técnica.

\subsection{Sobre o Projeto:}

Dos entrevistados na pesquisa 100\% relataram que tiveram dificuldades no projeto arquitetônico, principalmente no dimensionamento e disposição dos ambientes, dificuldade comum entre os principais autores, os proprietários, essas dificuldades resultaram em modificações do projeto prédefinido, para adequação de novos cômodos e ajustes das dimensões.

Todos entendem a importância de ter um projeto, embora não tendo ideia de valores mencionaram que estariam dispostos a pagar entre $\mathrm{R} \$ 400,00$ e $\mathrm{R} \$ 4.000,00$ pelo projeto.

\subsection{Sobre os Materiais:}

Em sua maioria também citaram que buscaram materiais conforme preço, devido à falta de conhecimento técnico. Outro fator observado foi que não realizaram medição para compra de material e à medida que os materiais iam acabando eles compravam, tornando assim o custo ainda maior pois a quantidade gera desconto, o construtor pode comprar direto do distribuidor, tornando a obra ainda mais onerosa. Em sua totalidade o concreto foi produzido in loco sem controle de Fck podendo, futuramente, gerar patologias.

\subsection{Sobre a Mão de Obra:}

A mão de obra dos casos apresentados foi mista, ou seja, parte remunerada e parte ajuda mútua, apenas o Caso II optou por mão de obra totalmente remunerada.

Percebe-se, portanto, que a adoção da autoconstrução se dá pela condição financeira. Os construtores acreditam que a contratação de um profissional técnico é cara e inviável, relatam que o custo que essa contratação gera atrasaria a construção, "O que gastaria nessa parte já compro de materiais", relata um dos entrevistados.

No geral as obras foram realizadas sem estimativas de custo, consequentemente, todas apresentaram custos acima do esperado ao final da construção. O pensamento do proprietário é sempre o mesmo: economizar.

Alguns ficaram com dúvidas quanto à fundação e acabaram fazendo baseado em experiências anteriores dos pedreiros. Os autoconstrutores confiam cegamente nos seus saberes e nas experiências dos pedreiros contratados, ficam satisfeitos com os resultados obtidos. 


\section{CONCLUSÃO}

As discussões apresentadas no entorno da pesquisa expuseram as principais características da autoconstrução por uma perspectiva geral, enfatizando os principais riscos aos quais essa modalidade construtiva está sujeita bem como a geração de despesas excessivas na obra, pois a falta de projeto e planejamento geram custos e desperdícios o dito, "barato que sai caro" visto que a obra planejada gera economia e supera os gastos com a contratação de engenheiro ou arquiteto. Toda essa discussão aponta para a necessidade de atenção evidenciando a importância da contratação e um devido acompanhamento por um profissional devidamente qualificado e habilitado com finalidade de conscientização acerca dos problemas que a ausência de qualificação técnica pode trazer, não só após a finalização da obra, mas durante sua construção. Os trabalhadores se submetem a riscos com a falta dos Equipamentos de Proteção Individual - EPI e Equipamentos de Proteção Coletiva - EPC, e orientações quanto à necessidade de uso deles, além de trabalharem de forma clandestina, que em um eventual acidente de trabalho não haverá um aparato legal.

Outro risco apresentado é a não preocupação com a legalização da obra, sujeitando os mesmo a embargos e/ou multas, colocando em risco a finalização da obra, visto a despesa "inesperada" para a legalização dela.

Os processos construtivos, no geral, foram realizados de modo empírico, oferecendo risco a seus ocupantes, pois se embasam em outras experiências de construção, as quais não servirão para uma outra construção, visto que muitos fatores são determinantes para a definição do processo construtivo mais adequado à cada situação.

\section{REFERÊNCIAS}

Almeida, S. L. L. C (2019). Um olhar sobre a autoconstrução, 33 pag. Trabalho de Conclusão de Curso de Especialização em Gerenciamento de Obras do Departamento Acadêmico de Construção Civil.

Associação Brasileira de Normas Técnica. (2004). NBR 9050: Acessibilidade a edificações, mobiliário, espaços e equipamentos urbanos. Rio de Janeiro.

Associação Brasileira de Normas Técnica. (2013). NBR 15575-1: Edificações habitacionais Desempenho - Parte 1: Requisitos gerais. Rio de Janeiro.

Associação Brasileira de Normas Técnica. (2014). NBR 6118: Projeto de estrutura de concretoprocedimento. Rio de Janeiro.

Balthazar, R. D. S. (2012). A permanência da autoconstrução: um estudo de sua prática no município de vargem grande paulista. 2012. 147 f. Dissertação (Mestrado) - Curso de Arquitetura e Urbanismo, Universidade de São Paulo, São Paulo.

Bonduki, N. (1998). Origens da habitação social no Brasil: arquitetura moderna, lei do inquilinato e difusão da casa própria.

Braga, M. L. A. (2001). Projeto para produção da autoconstrução. (2001). 74 f. Dissertação (Mestrado) - Curso de Tecnologia e Construção de Edifício, Instituto de Pesquisas Tecnológica de São Paulo - IPT,SãoPaulo. 
CAU/BR Conselho d Arquitetura e Urbanismo do Brasil. Pesquisa CAU/BR e Datafolha 2015. Disponível em: https://www.caubr.gov.br/pesquisa2015/ Acesso em: 15 mar. 2020.

Corsini, Rodnei. Trinca ou fissura: Como se originam, quais os tipos, as causas e as técnicas mais recomendadas de recuperação de fissuras. São Paulo: Techne Pini, jun. 2010.Disponível:http://techne.pini.com.br/engenhariacivil/

Ferro, S. A casa popular, Arquitetura Nova. São Paulo, São Paulo, Grêmio da Faculdade de Arquitetura e Urbanismo, Universidade de São Paulo, 1979.

Fragozo, S. D. (2016). O Desempenho das Construções no Processo de Autoconstrução de Habitações Populares. 2016. 135 f. Dissertação (Mestrado) - Curso de Engenharia Civil, UniversidadeFederaldoRiodeJaneiro, RiodeJaneiro.

Grandiski, Paulo. Entrevista concedida a Rodnei Corsini. Jul. 2010 Trinca ou fissura: Como se originam, quais os tipos, as causas e as técnicas mais recomendadas de recuperação de fissuras. SãoPaulo:TechnePini,jun.2010.Disponível:http://techne.pini.com.br/engenhariacivil/160/trincaou fissuracomoseoriginmquaisostipos2854881. aspx. Acesso em: 16 jul. 2010.

Lakatos, E. M.; Marconi, M. A. (2033). Fundamentos de metodologia científica. 5. ed. São Paulo: Atlas.

Lei $n^{\circ} 11.888$, de 24 de dezembro de 2008. Assegura às famílias de baixa renda assistência técnica pública e gratuita para o projeto e a construção de habitação de interesse social e altera a Lei no 11.124, de 16 de junho de 2005.

Maricato, E. “Autoconstrução, a arquitetura possível”. In: MARICATO, E. (org) A produção capitalista da casa (e da cidade) no Brasil industrial. São Paulo: Alfa Ômega, 1979.

Ministério de Trabalho. Norma Reguladora $N^{o}-35$ : Trabalho em altura. Portaria SIT n. ${ }^{\circ}$ 313, de 23 de março de 2012. Publicada no D.O.U em 27 de março de 2012.

Ministério de Trabalho. Norma Reguladora $N^{o}$ - 6: Equipamento de proteção individual - EPI. Portaria MTb n..$^{\circ}$ 3.214, de 08 de junho de 1978. Publicada no D.O.U em 07 de julho de 1978. Souza, M. F.; Stephan, I. I. C.; Carvalho, A. W. B. Modos de vida e modos de habitar na moradia autoconstruída. Risco: Revista de Pesquisa em Arquitetura e Urbanismo (online), v. 16, p. 37-54, 2018. 